\title{
Experimental studies on seed production of tropical grasses in Kenya. 1. General introduction and analysis of problems
}

\author{
J. G. Boonman
}

National Agricultural Research Station, Kitale, Kenya

Received : 10 September 1970

\section{Summary}

The development of grass seed production in Kenya is described. A discussion is given of the problems in seed growing, of which the most pressing are the low yield and quality of the seed. Low yields and quality are due to:

- prolonged head emergence within plants;

- prolonged flowering within heads;

- decreased duration of flowering in late emerged heads;

- low seed setting;

- low number of head producing tillers;

- extended spread in heading time between plants in a variety;

- other factors including low seed retention, spikelet diseases and bird damage.

All cultivated varieties show a varying combination of these factors.

Some results, together with ways of improvement through agronomic techniques and breeding, are presented and discussed.

\section{Introduction}

In recent years, many tropical countries have made increased efforts to raise livestock productivity through improved grazing. Depending upon the previous level attained, as well as upon economic incentives, the spectrum of ways of improvement may range from simple controlled herding to sophisticated practices of sown pastures receiving nitrogen dressing and supplementary irrigation. In farming systems where little progress can be accomplished by further exploitation of the available natural grazing and where a minimum level of efficient grassland and livestock husbandry has been achieved, attention will primarily be focussed on artificial pastures, planted to productive grass varieties.

The planting of a pasture obviously necessitates the supply of planting material which can be either vegetative plant parts or seed. A number of tropical grasses have, thus far, only been propagated vegetatively from splits, stem cuttings, stolons or rhizomes. Of these grasses, Pennisetum purpureum, Pennisetum clandestinum, Digitaria decumbens and Cynodon spp. are in widespread use throughout the tropical world. These species combine poor seeding properties with excellent ability for vegetative reproduction, either because they cover the ground quickly through creeping or merely due to the size an individual tufted plant may reach in a short time. Occasionally, certain grasses which could be grown from seed, are propagated vegetatively if seed 
is scarce or considered expensive. Unless various operations are mechanized, as in the southern parts of the USA where large areas are planted annually to Cynodon dactylon (Burton, 1966), vegetative propagation is very labour- intensive. Its success depends further on weather conditions after planting. A dry spell kills vegetative material quicker than seed (Bogdan, 1965b).

In general, preference is attached to the use of seed when available and, in fact, efforts are being directed towards developing seeding varieties of species hitherto propagated only vegetatively, such as Cynodon spp. (Burton, 1966; Bogdan, 1966). Work is in progress in Australia on the development of a seeding variety of Pennisetum clandestinum (Wilson, 1970).

In Kenya, only Pennisetum purpureum is propagated vegetatively on a large scale. It differs from normal pasture grasses in that it forms large tufts which are planted in wide rows, sometimes up to $3 \mathrm{~m}$ or more. Such plantings are drought-tolerant and have gained popularity for grazing in the dry season.

\section{The development of grass seed production}

For normal pastures only varieties which can produce economic amounts of seed have become popular in Kenya. Their profitable inclusion in farm rotation became apparent before the last world war in the major large-scale cereal growing areas where livestock production proved feasible. The main objective is to have a resting period with productive grass varieties for livestock, instead of the ordinary tumble-down pastures. After three to four years the pasture, normally referred to as ley, is ploughed out and planted to crops. Varietal use as governed by various climatic conditions in Kenya has been discussed by Bogdan (1960). Over $80 \%$ of Kenya receives insufficient rainfall for sustained crop production (FAO, 1969). The following only applies to those areas with adequate rainfall situated at the medium and higher altitudes, normally referred to as 'high potential' areas.

At high altitudes, above $2250 \mathrm{~m}$, where year round mean monthly temperatures are lower than those of summer in the south of U.K. (Bogdan, 1960), species such as Lolium perenne and Dactylis glomerata are used extensively. Seed has to be imported as local yields are low due to limited heading in the absence of specific daylength and cold winter (Birch, 1958). At medium altitudes, however, only local tropical varieties are used. Before the advent of selected varieties in the mid fifties it was common among farmers to harvest seed of natural, dominant stands of Chloris gayana and Melinis minutiflora for farm use or sale. Names such as Rongai or Endebess Rhodes were used according to the area of origin.

With the opening of the Grassland Research Station, since 1963 incorporated in the National Agricultural Research Station, at Kitale, a serious attempt was initiated to explore the wealth of genetic material available in Eastern Africa, known to be the centre of origin of most tropical grass species. Over 4000 introductions, out of the local flora, were screened by A. V. Bogdan and R. Strange, out of which the best 9 varieties are at present under commercial seed multiplication (Table 1). Their breeding behaviour and botanical characteristics have been described by Bogdan (1959a; 1965a).

The Agricultural Census of 1960 estimated that the area under grass leys was about 80,000 ha and since then a considerable increase has undoubtedly taken place. However, reliable and up to date figures are available only for the Trans Nzoia District, 
Table 1. Names and mode of reproduction of varieties grown from seed in Kenya, together with area under seed production in 1970.

\begin{tabular}{llc}
\hline Name & $\begin{array}{l}\text { Mode of re- } \\
\text { production }\end{array}$ & $\begin{array}{l}\text { Area in 1970 } \\
\text { (ha) }\end{array}$ \\
Setaria sphacelata cv. 'Nandi I' & C & 200 \\
Setaria sphacelata cv. 'Nandi II' & C & 200 \\
Chloris gayana cv. 'Mbarara' & C & 250 \\
Chloris gayana cv. 'Masaba' & C & 100 \\
Chloris gayana cv. 'Pokot' & C & 500 \\
Panicum coloratum cv. 'Solai' & C (?) & 100 \\
Panicum maximum cv. 'Makueni' & A & 20 \\
Brachiaria ruziziensis & A (?) & 5 \\
Melinis minutiflora cv. 'Kitale' & A (?) & 5 \\
& & 1380 \\
\hline
\end{tabular}

$\mathbf{C}=$ cross-pollinating; $\mathbf{A}=$ apomictic.

of which Kitale is the centre. A survey held in this district has shown that $9.4 \%$ of all available grazing was under planted leys, involving some 17,500 ha. Trans Nzoia District comprises only about $5 \%$ of the high-potential areas of Kenya, leading one to suggest that an overall area of 350,000 ha could be expected assuming an equal proportion of leys in the other districts. The latter is certainly not correct as figures of seed sales indicate that one third of all grass seed offered for sale is sold to farmers in the Trans Nzoia District.

As mentioned above, grass seed production in Kenya started off with the harvesting of seed from natural stands. With the advent of selected varieties, initial bulking remained in Government hands for some years. In 1956 the Kenya Seed Company was set up at Kitale by grass seed growers, and this gave a strong impetus to the production, processing and marketing of seeds of selected varieties. The expansion in the area under grass seed production in the last 10 years is shown in Table 2.

This increase in area obviously mirrors the increase in demand which, as yet, has exceeded the supply of seed. It is of particular interest to note that the small farmers are increasingly becoming aware of the profitability of sown pastures. Not only Kenya is developing its livestock industry, but so are many other tropical countries. Considerable quantities of seed, particularly of Chloris gayana and Setaria sphacelata, have been exported to Australia, Japan and neighbouring countries like Uganda and Tanzania. The outstanding performance of Kitale varieties has also been shown in countries as different as Madagascar, Cameroon and Guyana (Borget, 1969). No other

Table 2. The increase in area under grass seed production.

\begin{tabular}{lc}
\hline Year & Area (ha) \\
1961 & 100 \\
1962 & 200 \\
1966 & 500 \\
1967 & 600 \\
1968 & 700 \\
1969 & 800 \\
1970 & 1400 \\
\hline
\end{tabular}


country has yet been engaged in production for exporting tropical grass seed so that the prospects are bright for Kenya.

\section{Current seed growing practices}

Since most of the seed is produced on mixed farms where maize and livestock production are the two major undertakings, grass seed production was decidedly a sideline in the early years and was seldom regarded as an integral part of the farming system. Cereal prices were high in contrast to the relatively low economic return from grass seed growing and at that time growers had not much experience of techniques. In addition, as livestock production was a major part of the farming system, a grower would close up a pasture for taking a seed crop only if grazing was not limited on the farm. However, maize prices have gone down by about $33 \%$ since 1965 and are expected to remain at this level for some time. Equally important is that growers have obtained more experience in handling the grass seed crop. As a result, nearly every grower will now make an effort to obtain at least one seed crop a year and many of them will aim at a second crop by the end of the season. Even then, an appreciable amount of grazing is still left in the aftermath herbage.

To explain this system of multi-cropping it is important to look at the climatic conditions of the Kitale area where most of the seed is grown. Kitale $\left(1^{\circ} \mathrm{N}\right)$ is situated at nearly $1900 \mathrm{~m}$ altitude. Mean monthly temperatures are on average $19.1^{\circ} \mathrm{C}$ in February, $19.4^{\circ} \mathrm{C}$ in March and $19.3^{\circ} \mathrm{C}$ in April, which are the warmest months. In the coolest months these temperatures are 17.2 and $17.3^{\circ} \mathrm{C}$ for July and August (Woodhead, 1968). Maximum day temperatures are seldom above $30^{\circ} \mathrm{C}$ and minimum night temperatures are rarely below $9^{\circ} \mathrm{C}$. The variation in daily temperatures is, therefore, much greater than between months. Near the Equator solar daylength is about 12 hours. At $1^{\circ} \mathrm{N}$ solar daylength only varies by 9 minutes over the year. The rainy season usually starts in late March and continues until late November, with most of the rain being received between March and September. December till March is normally dry. Average annual rainfall is nearly $1200 \mathrm{~mm}$.

With this type of climate it is feasible to obtain 2 full seed crops a year. Following sowing in early April, the first seed crop will be ready in August or September and a light second crop can be reaped from the aftermath by the end of the season. In the second and subsequent years, following a cleaning cut and topdressing with nitrogenous fertilizer at the onset of the rains, a first crop can be harvested in June or July and a second full crop in October or November.

Up till now, seed growing practices have been rather haphazard. Most species, whether stoloniferous or tufted, were given a similar treatment. The standard drill width is $90 \mathrm{~cm}$. This is largely determined by the customary width of maize implements rather than by a proven superiority of any given width of drill. This row width became popular at a time when mechanical cultivation was regarded as indispensable for weed control and for supposed soil-improving purposes. The standard seeding rate is the equivalent of $1 \mathrm{~kg} / \mathrm{ha}$ of Pure Germinating Seed (P.G.S.). Phosphate fertilizer at a rate of $50 \mathrm{~kg} \mathrm{P}_{2} \mathrm{O}_{5}$ is normally mixed with the seed prior to planting. Both hand and machine planting are practiced. Shallow planting is essential (Bogdan, 1964) and rolling favours rapid germination. Normally, various combinations of mechanical cultivation, hand weeding and herbicides, mainly 2,4-D, are used for weed control. If weed control is inadequate no seed harvest is taken until the crop itself has grown 
away from annual weeds with the aid of the grazing cow and a rotary slasher. The latter practice means a loss, however, since the first year crop yields well, with little or, normally, no nitrogenous fertilizer. In the second and subsequent years topdressing with $60 \mathrm{~kg} \mathrm{~N}$ per ha is carried out at the beginning of each growth cycle, although economic returns have been obtained from over $100 \mathrm{~kg} \mathrm{~N}$ per ha. Higher rates of $\mathrm{N}$ also result in more aftermath herbage for grazing.

Determining the right stage for seed harvesting is difficult. Most growers decide to delay harvesting until part of the seed has shed, which is normally 7 or 8 weeks after initial head emergence. Harvesting is either carried out with a reaper binder, if labour is scarce, or by hand with sickles. Heads are cut off above the leaf canopy, bound and stooked in the field. Some two weeks later stooks are collected and threshed, normally by beating the seed out with sticks on a sheet. Rough particles are sieved out and the seed is dried in the sun before being taken to the seed firm for cleaning and processing.

Burning seed fields after grazing is practiced at the end of the dry season to get rid of excess foliage. It certainly is also a hygienic practice to destroy crop debris harbouring diseases and pests.

Seed fields can economically be maintained in a productive stage for at least four years, if kept reasonably free from perennial grass weeds.

A new certification scheme covering all important seed crops has been initiated in 1969. Legislation and rules are in compliance with those of OECD. Under this scheme, basic seed denoting breeder's seed as well as elite seed will be produced under the supervision of the breeder, for the production of certified seed on growers' farms.

Another promising development in the grass seed industry has been the setting up of a seed growers association. Once established fully, it will provide a useful medium for contacts with seed firms and government institutions.

\section{Problems in grass seed growing}

The most pressing problems are of a crop-physiological and genetical nature; these will be discussed later. At this stage, however, some of the technical problems in the above practices need to be mentioned.

Mechanization of harvesting and weed control, the overriding subjects of research on grass seed production in temperate countries, do not require urgent attention in Kenya as long as hand labour remains the most practical, economic and least weatherdependent way of handling a seed crop. In fact, labour-intensive methods are to be preferred in countries faced with acute unemployment problems. With maximum use of hand labour 15-20 man-days are required per hectare for all operations between the cutting of heads and delivery of uncleaned seed to the seed firm. At the present wage level, costs of hand labour would still be only $30-50 \%$ of the costs of mechanized combine-harvesting, even if this were at all feasible. In fact, preliminary trials with combine-harvesters have shown discouraging results. Seed is of inferior viability and there are very great problems with the first crop which matures in the wettest months. Worst of all, a good seed crop is mounted on some 8-10 tons of herbage dry matter, which is decidedly difficult to pass through a combine, even when allowed to dry in wind-rows after mowing. Unless heads are cut under dry conditions, seeds will shatter readily on the ground if not protected in well covered stooks. As a compromise, reaper binders are used extensively in peak periods when labour is scarce. 
As far as weed control is concerned, 2,4-D herbicides are economically applied against a wide range of broad-leaved weeds, but hand weeding is the most effective method against obnoxious annual and perennial grass weeds. Problems of seed cleaning are under investigation (Oomen, 1969). Storage and seed longevity pose relatively few practical difficulties since most grass species do not reach maximum seed maturity until six months after harvesting, and most of them retain this for over two years (Moore, 1962). In the warm and humid tropics at low altitudes, however, grass seed longevity is a major limiting factor (Behaeghe, 1960).

Given adequate rainfall and nitrogen supply, seed crops of Setaria sphacelata and Chloris gayana will mature within 3-5 months after the cleaning cut. Provided the first crop is allowed to commence growth at the onset of the rains, 2 crops can be obtained, while still allowing sufficient time to utilize the herbage after the first seed harvest. This herbage can amount to 6-8 ton per ha of dry matter, with a crude protein percentage as high as 7\% (Dougall, unpublished data). Most growers regard the utilization of this good quality herbage left after the seed crop as being an essential part of the whole enterprise. After the second seed crop, coinciding with the onset of the dry season, direct grazing is the most economic method even though losses due to trampling and fouling are considerable. After the first seed crop, however, when rainfall is normally high, such utilization through direct grazing is less urgent on account of the abundant grazing then available in the actual pastures on the farm. Grazing may take a considerable period and leave insufficient time for a complete growth cycle of the second crop; particularly if the first seed crop is already late. A better proposition would be to conserve this herbage as silage for feeding during the dry season, when the supply of cheap fodder is limited on most farms. Whether grazing or ensiling is practiced, either of the two is better than merely slashing the herbage, leaving it in the field and topdressing with nitrogen over it. Apart from the loss of quality fodder, regrowth is seriously hampered by the thick layer of slashed grass on the ground and it can safely be assumed that nitrogen is withdrawn to make the slashed herbage decompose.

The most pressing problems are presented by the low seed yields and the low percentage of Pure Germinating Seeds (P.G.S.) normally encountered. Present annual seed yields in commercial fields rarely exceed $200 \mathrm{~kg} / \mathrm{ha}$ while a P.G.S. percentage of 25 is considered good. Consequently, effective annual seed yields of more than $50 \mathrm{~kg}$ P.G.S. per ha are exceptional. This compares very unfavourably with seed yields of grass species in temperate climates, where effective seed yields of over 1000 $\mathrm{kg} / \mathrm{ha}$ are common in many varieties. On the other hand, $1 \mathrm{~kg}$ P.G.S. is adequate to establish 1 hectare of pasture (Strange, 1957), pointing to a multiplication factor of 50 .

Table 3. Costs of seed for the establishment of 1 ha in 1970.

$\begin{array}{ll}\text { Seed rate } & \text { Costs } \\ \text { (kg P.G.S.) } & \text { (Kshs) }\end{array}$

Ley of tropical grass

Ley of temperate grass

Hybrid maize

Sunflower

$\begin{array}{rr}1 & 100 \\ 4 & 25 \\ 20 & 50 \\ 7 & 20\end{array}$

Seed costs as a

percentage of total establishment costs

1 Ksh. = 1 Kenya shilling $=$ US $\$ 0.14$ 
But even then, the seed costs for establishing one hectare of a tropical grass still compare unfavourably with the costs incurred when planting pastures with imported seed of the temperate grasses used at high altitudes in Kenya, as mentioned above. A comparison of seed costs is given in Table 3 , including also the seed costs of two common annual crops.

Although the seed costs are depreciated over a number of years, it is evident that the high cash expenditure deters many farmers who are not familiar with the ultimate profitability of sown leys. Consequently, the use of selected, productive varieties remains below the potential, which, in turn, restricts demand and expansion in seed production area. This vicious circle can most effectively be broken by finding out how to make a substantial increase in effective seed yields per hectare.

\section{Causes of low seed yield (literature review)}

Surprisingly little experimental work has been conducted on field problems of seed production in tropical grasses, although a considerable amount of chiefly cytogenetical research work has been carried out on some grasses normally propagated vegetatively, such as Digitaria decumbens, Pennisetum clandestinum, Setaria splendida, Pennisetum purpureum and Cynodon spp.

The Pangolagrass variety of Digitaria decumbens, widely used in the southern USA and the Caribbean, is a sterile interspecific hybrid, producing numerous flowering heads but no viable seed (Sheth et al., 1956). Both male and female sterility were found to cause this. Male sterility is also encountered in Pennisetum clandestinum either due to low temperatures (Youngner, 1961) or to cytological irregularities (Hrishi, 1952). Carr and Eng Kok $\mathrm{Ng}$ (1956) observed an increase in flowering following severe defoliation. This is commonly observed in Kenya on lawns planted to this grass.

Setaria splendida displays a high degree of pentaploidy and heptaploidy which apparently causes the very low yields of viable seed normally obtained (Hacker, 1966).

In Pennisetum purpureum, only few varieties produce heads in Kenya but never abundantly. This species has been crossed in a number of countries with Pennisetum typhoides, a cereal, to produce hybrids possessing amongst other qualities better seeding properties.

Kenya varieties of Cynodon spp., known as star grass, produce few flowering heads and little seed, necessitating vegetative propagation. Attempts have been made to develop a seeding variety (Bogdan, 1966) but progress is hampered by the occurrence of Claviceps and Ustilago spp. affecting the spikelets. Cynodon dactylon var. dactylon, known as Bermuda grass, has been the subject of intensive breeding work in the USA (Harlan, 1970). Many hybrids were developed for vegetative propagation. Over 2.5 million hectares are planted to Coastal Bermuda grass. A need is, however, felt to develop seeding varieties (Burton, 1966).

It has been mentioned above that these species combine poor seeding properties with excellent suitability for vegetative propagation. They are, invariably, highly productive varieties in many parts of the world. The ease of vegetative reproduction has been of great adaptive significance in the absence of an adequate mechanism for generative reproduction.

Returning to the seed-multiplied grasses, it is now important to discuss some theories that are sometimes adduced. Very little field experimentation has been conducted, and this has led to some generalized statements to explain the poor seeding proper- 
ties of tropical grasses. It has been said that most tropical grass species belong to tribes having an inherently low potential for seed yield. These tribes are the Paniceae and the Andropogoneae. Among these, however, some important cereals have evolved such as Panicum miliaceum, Setaria italica, Pennisetum typhoides and Sorghum vulgare.

Another suggestion is that tropical grasses have been subject to little or no domestication for seed production. In comparison with cereals this is certainly true. However a considerable number of good seeding varieties of temperate grass species originate from the wild flora in much the same way as varieties of tropical grasses.

It has also been suggested that apomixis which is unusually common in the Paniceae and Andropogoneae, is associated with poor seeding properties (Bogdan, 1959a). Warmke (1954) reporting on a cytological study suggests that the low seed yielding ability of Panicum maximum, a facultative apomict, is due to degeneration of all tour reduced megaspores, without apospory, and due to occurrence of more than one embryosac within an individual ovule. Panicum maximum is certainly the poorest seeder of all commercial species in Kenya. Seed yields, however, of Melinis minutiflora, probably also an apomict, are comparable with those of the best cross-pollnating species. Also seed yields of the temperate apomict. Poa pratensis, can be very high (Evers and Wolfert, 1959). In general, apomixis is considered to be of great adaptive significance to overcome cytogenetical barriers. On the other hand, it can be seen from Table 1 that the seed production area under apomictic species is only very small.

Little or no seed is often obtained from single-clone plantings owing to self-incompatibility. Where vegetative propagation is practiced on a commercial scale, plants often derive from one single superior genotype.

Reviewing the above literature is appears necessary to study the main factors affecting seed yield under field conditions from the beginning. It is especially important to study the various aspects of flowering which is generally known to be extended.

\section{An analysis of factors affecting seed yield}

Crop physiological studies carried out by the author since 1966 have shown that seed yield and P.G.S. percentage are low due to seven main reasons.

1 Prolonged head emergence within plants. Individual plants of tropical grasses show head emergence over a period of up to 3 months or longer. Even under crop conditions this was found to result in the following generalized patterns of head emergence (Fig. 1).

Varieties differ as to the degree of concentration in head emergence and this is immediately reflected in the seed yields. Panicum coloratum heads rapidly and is a very good seeder. Panicum maximum, however, heads almost continuously and is, therefore, a poor seeder. Peak emergence, i.e. the stage when most heads emerge per week, is normally around the 6th week. Initial head emergence is here defined as the stage when 5 to 10 heads have emerged per $\mathrm{m}^{2}$.

It is evident that this pattern of head emergence in tropical grasses is in sharp contrast to that of cereals in general and of grasses in temperate countries in which heading is concentrated in a very short period, often only a matter of a few days. Experience has also shown that tropical grass varieties commence heading and produce 
Number of emerged heads per $\mathrm{m}^{2}$

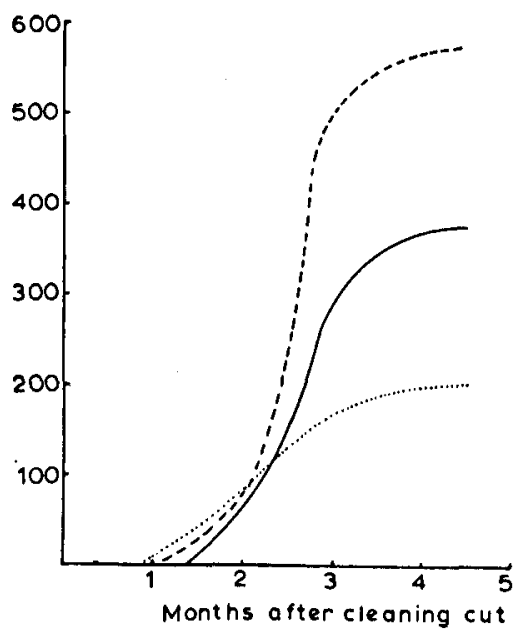

Fig. 1. Schematic representation of head emergence in crops of three cultivated species of tropical grasses.

- - Panicum coloratum cv. 'Solai'; _L Setaria sphacelata cv. 'Nandi I'; ....... Panicum maximum cv. 'Makueni'.

a good seed crop at any time of the year provided rainfall and nitrogen supply are not limiting. Under such conditions heading will commence 3-10 weeks after the cleaning cut. The length of this pre-heading period depends on variety, age of the crop since planting, stage of growth at which the last preceding crop was cut, and on weather conditions. Cold weather appears to prolong the pre-heading period. Heading is also delayed by burning the immediately preceding crop.

Reviewing the sparse literature on daylength responses in tropical grasses Evans (1964) suggests that the small seasonal changes in tropical daylengths may have marked effects on inflorescence initiation, as in several rice and sugar-cane varieties.

However no evidence exists to suggest that the solar daylength variations of some 9 minutes at Kitale have a visible effect on heading in Kitale varieties. Head initiation might be different at other latitudes. However even in Israel and the southern parts of the USA, both north of $30^{\circ} \mathrm{N}$, more than two seed crops can be taken of Chloris gayana per year, obviously in different seasons with different daylength regimes (Gordin-Sharir, 1966; Wheeler, 1950).

It has been mentioned already that Kitale varieties are grown in many countries, even beyond the tropics of Cancer and Capricorn. Very few data are available on seed yield and $\%$ P.G.S. of Kitale varieties at other latitudes, but, even then, it would not be justifiable to ascribe higher or lower yields solely to differences in daylength.

The impact of prolonged heading on seed yield has been discussed by Boonman (1967). Since seeds usually begin shedding within 4-5 weeks after the particular head has emerged, a loss of seed is incurred, no matter when the crop is harvested, due to shedding in early emerged heads and incomplete seed formation in late emerged heads, while a proportion of heads is still enclosed in the leaf sheath. Determining the optimum time of harvesting, i.e. the time at which the highest amount of completely formed seed can be harvested is, therefore, of utmost importance.

2 Prolonged anthesis and stigma exsertion within single heads. In Setaria sphacelata anthesis and stigma exsertion, i.e. the actual flowering, were found to continue for 7 weeks (Table 4). It is indeed quite common in varieties of this species to find 
Table 4. Duration of flowering and mean head length in successive weekly age-groups of head emergence in a seed crop of Setaria sphacelata cv. 'Nandi II'.

\begin{tabular}{lrrrrrrrrrrrrrr}
\hline \multicolumn{11}{c}{ Age-group of head emergence (weeks) } \\
\cline { 2 - 3 } & 1 & 2 & 3 & 4 & 5 & 6 & 7 & 8 & 9 & 10 & 11 & 12 & 13 & 14 \\
$\begin{array}{l}\text { Duration of flow- } \\
\text { ering (weeks) }\end{array}$ & 7 & 7 & 5 & 2 & 2 & 2 & 1 & 0 & 1 & 0 & 0 & 0 & 2 & 2 \\
$\begin{array}{l}\text { Mean head } \\
\text { length (cm) }\end{array}$ & 18 & 17 & 19 & 19 & 19 & 19 & 19 & 18 & 18 & 17 & 16 & 13 & 13 & 13 \\
\hline
\end{tabular}

abundant flowering, even in the early emerged heads, on the optimum date of harvesting, normally some 6 weeks after initial head emergence. Consequently, it is not uncommon to find shedding and flowering within the same head. The ear-like panicles of Setaria sphacelata are relatively long (Table 4). In the digitate panicles of Chloris gayana cv. 'Mbarara', individual racemes are rarely longer than $8 \mathrm{~cm}$ and this may explain why anthesis within heads of this variety is completed within 3 weeks. Bogdan (1959b) found flowering within racemes in the Kerio variety of this species completed in only 2 weeks.

3 The decreasing duration of flowering and decreasing headlength in progressively later emerging heads. Observations were made in an area of $6 \times 7.2 \mathrm{~m}$ of a first year's seed field planted in $90-\mathrm{cm}$ rows. Heads emerging during a particular week were labelled at the end of that week with coloured chicken rings. Flowering was recorded every two days and the mean head length of every weekly age-group was determined. The observations continued for 14 weeks by which time the crop became so aged that new tillers and heads began to appear through.

It can be seen from Table 4 that the early formed heads flowered over a period of 7 weeks. Later emerged heads flowered progressively shorter and no flowering was observed after the 7 th week. No evidence was found that later emerged heads flowered more intensively during their short period of flowering. Flowering appeared again with the 13th week, probably due to the opening up of the aged leaf canopy.

The mean head length decreased from $19 \mathrm{~cm}$ at the maximum to only $13 \mathrm{~cm}$ at the end. The earliest heads were somewhat shorter than those with maximum head length. This has been observed on many other occasions, also in Chloris gayana. In both species, overall mean head length is longest in the first year's harvest and is reduced to about $60 \%$ in subsequent years.

Although the percentage of seed setting per head could not be determined due to the technical difficulties involved, it can safely be assumed that the seed setting efficiency decreased progressively as head emergence continued (Anslow, 1963).

Also in seed crops of Chloris gayana a similar situation was observed. Both number of racemes per head and mean raceme length decreased at progressively later stages of heading.

The above may also explain why optimal time of seed harvesting is normally earlier than one would calculate on the basis of a head emergence curve. For seed seting is apparently better in early emerged heads than in those of peak emergence and subsequent groups.

4 Low seed setting per head. A head of Setaria sphacelata of average length $(12 \mathrm{~cm})$ bears 500-750 single spikelets each with one fertile floret (Gildenhuys, 1950). The 
1000 -grain weight of clean seed is normally around $350 \mathrm{mg}$. At maximum seed setting, i.e. when all spikelets contain viable caryopses, an average head could produce some $200 \mathrm{mg}$ of Pure Germinating Seed. By simply dividing overall yield of P.G.S. by the number of heads concerned in various field experiments, the average yield of P.G.S. per head does not exceed $20 \mathrm{mg}$, thus only $10 \%$ of the potential. In view of (3) early emerged heads may produce considerably more than this and later emerged heads considerably less.

Obviously, the low average percentage of seed setting does not stand on its own, since (1), (2) and (3) are deeply involved which may mask the actual potential of individual spikelets to set seed. Also Burton (1943) reported low seed setting in a number of tropical grasses.

5 Low number of head producing tillers. In the course of experiments it was observed that the head number per $\mathrm{m}^{2}$ in average seed crops of Setaria sphacelata and of Chloris gayana rarely exceeded 200 and 250, respectively.

Working on temperate grasses, Evans (1959) observed up to 280 heads in cocksfoot $S 143,680$ in timothy $S 48$ and 1450 heads in perennial ryegrass $S 23$. Considering that the ear-like panicles of Setaria resemble timothy panicles in appearance and length, it becomes evident that the observed head numbers limit seed yield in tropical grasses. Concurrently, only a small proportion of the tillers formed - up to 2500 tillers per $\mathrm{m}^{2}$ have been observed in Setaria sphacelata at stages prior to initial head emergence - produces an emerged head at harvesting time.

6 Large variation in time of initial head emergence between plants within a variety. Kitale grass varieties showed an unusually extended spread in time of initial head emergence and subsequent seed maturation between plants. This is well illustrated by the results given in Table 5 for Chloris gayana cv. 'Pokot'. 758 spaced single-plant plots of $2.5 \times 2.5 \mathrm{~m}$ were scored weekly for initial heading which denotes first head emergence when commencing all over the plot. The field was in its third year.

A similar extended spread has also been noticed in other varieties and species. Needless to say, such a wide variation leads to a considerable loss of seed due to a correspondingly wide variation in date of maturity. The first plants are ready for harvest when the last plants just begin heading.

In addition, this wide variation implies unsatisfactory inter-plant fertilization and a greatly increased risk of genetic shift. It can be seen from Table 5 that most plants produce initial heading in the first 3-4 weeks. The chance that the first and last groups intercross is very small. The obvious consequence of this would be that successive generations will head at a progressively earlier date.

Evidence that this is actually happening in the Kitale grass varieties is illustrated in the following finding. Splits of Setaria sphacelata cv. 'Nandi I' were collected

Table 5. Percentage of plants showing initial heading.

\begin{tabular}{lrrrrrrr}
\hline \multicolumn{7}{l}{ Week } \\
\cline { 2 - 8 } & 1 & 2 & 3 & 4 & 5 & 6 & 7 \\
Percentage of plants & 4 & 19 & 19 & 22 & 16 & 14 & 6 \\
\hline
\end{tabular}


Table 6. Head numbers at initial heading and final seed yield in clones of Setaria sphacelata cv. 'Nandi I', temporarily grown under varying conditions (seed field $=100$ ).

\begin{tabular}{lcc}
\hline Origin of clones & $\begin{array}{l}\text { Head number at } \\
\text { initial heading }\end{array}$ & Seed yield \\
Seed field & 100 & 100 \\
Ley D & 65 & 89 \\
Ley C & 34 & 89 \\
Ley B & 26 & 82 \\
Ley A & 8 & 72 \\
\hline
\end{tabular}

during 1967 from 4 old leys in the Kitale area and from a seed field. The old leys had been planted some 10 years earlier at the time that the first seed of this variety was released. The seed field, however, originated from the same release but had subsequently been subject to at least 5 generations of continuous seed multiplication. 100 clones of each source were interplanted. Heads were counted at the initial heading stage and the seed yield was determined (Table 6).

The occurrence of shift is quite obvious. Unfortunately, the original parental clones could not be included since they were no longer available. It is, therefore, difficult to distinguish a tendency towards earliness in the seed field clones from a tendency to lateness in the clones deriving from the old leys.

It can, however, safely be assumed that both processes have taken place concurrently. Seed harvesting was carried out at too late a date for the seed field clones so that their seed yield was relatively low.

The difference between head numbers in clones from the various leys can be explained on the basis of the management history of these leys. Intensity of management and grazing had been best in ley $\mathbf{A}$ and had been decreasingly less in ley B, $C$ and $D$. This shows clearly that early types had been eliminated under intensive grazing of some 10 years.

The wide range in heading time, observed in the Kitale grass varieties, is the obvious result of uncontrolled, continuous seed multiplication. Parental stocks were not maintained and every new generation was established with seed from a previous one. This has necessitated renewed selection.

7 Other indirect limiting factors including seed shattering, spikelet diseases, bird damage and ease of lodging. Seed retention is a character which is not highly developed in the Kitale grasses. Like seed setting, seed retention does not stand on its own. Early emerged heads in early plants are bound to shatter their seed by the time the bulk of the crop is mature.

Tilletia echinosperma is a common spikelet disease in Setaria sphacelata and Panicum maximum. Occasional heavy infestations occur. Small seed eating birds are also quite a nuisance, especially in isolated small experimental fields.

The above 7 factors affect all varieties in varying combinations resulting in low yields and P.G.S. percentage. The Crop Index is very low, too. In Setaria sphacelata, to take one example, average annual yields of clean seed are $150 \mathrm{~kg}$ against a total of $15,000 \mathrm{~kg}$ harvested dry matter. The Crop Index is, therefore, only 1\% against $10 \%$ and $50 \%$ normally found in temperate grasses and cereals, respectively. 
Purely on the basis of seed yield components and irrespective of prolonged heading and flowering, a potential yield of $450 \mathrm{~kg} / \mathrm{ha}$ of P.G.S. can be calculated for an average crop of $S$. sphacelata $\left(200\right.$ heads per $\mathrm{m}^{2} \times 750$ seeds per head $\times 0.3 \mathrm{mg}$ per seed). This is $900 \mathrm{~kg}$ per year which approaches commercial yields in temperate grasses. Actual commercial seed yields in tropical grasses, however, are only $5 \%$ of this.

\section{Work in progress}

As a consequence of the above analysis of factors affecting seed yield, work is now in progress on field research along the following lines:

1 Given a particular pattern of heading in the field, to accomplish maximum yield of P.G.S. by determining the right harvesting time.

2 To influence the pattern of heading both by enlarging its scale and by concentrating this increased number over a shorter length of time.

Close tiller density in combination with the optimum level of nitrogenous fertilizer were found to be the major changes which attained these objectives and led to substantial increases in yield and P.G.S. percentage over traditional seed growing practices (Boonman, 1970).

3 On account of the great variation in heading time and the risk of genetic shift, all varieties listed in Table 1 have now been stabilized through the establishment of spaced-plant populations. Propagation material was obtained from present seed fields. Seed fields and not leys were chosen as source of material for the following reasons. Firstly, varietal name and history of the chosen seed fields were known with certainty. Secondly, benefit may be obtained from the natural selection, which will certainly have taken place towards better-seeding properties, rather than merely towards earliness and increased heading. Indeed, the spaced-plant populations offer useful variations in desirable characteristics, not only in head numbers but, more favourably so, also regarding concentrated heading, head length, seed setting and seed retention. On the herbage side, great variability exists as regards growth habit, vigour, leafiness and disease resistance. Seed yield rather than herbage productivity is considered to be the main factor limiting the use of Kitale grass varieties. The problems encountered when breeding for higher seed yields in herbage varieties have been discussed by Griffiths et al. (1966).

Throughout the course of field experiments, particular attention is given to patterns of tillering and head emergence and to the analysis of seed yield components. This approach was found to explain many of the problems, and also to increase the efficiency of field experiments.

\section{References}

Anslow, R. C., 1963. Seed formation in perennial ryegrass. 1. Anther exsertion and seed set. J. Br. Grassld Soc. 18: 90-96.

Behaeghe, T., 1960. Conservation et utilisation des semences de graminées. Bull. agric. Congo 51: 1223-1240.

Birch, W. R., 1958. Observations on the flowering of exotic pasture grasses in Kenya. E. Afr, agric. J. $24: 142-147$.

Bogdan, A. V., 1959a. The selection of tropical ley grasses in Kenya: general considerations and 
methods. E. Afr. agric. J. $24: 206-217$.

Bogdan, A. V., 1959b. Flowering habits of Chloris gayana. Proc. Linn. Soc. 170: 154-158.

Bogdan, A. V., 1960. Climate and grass breeding in Kenya. Proc. 8th int. Grassld Congr. 1960: 340-342.

Bogdan, A. V., 1964. A study of the depth of germination of tropical grasses: a new approach. J. Br. Grassld Soc. 19: 251-254.

Bogdan, A. V., 1965a. Cultivated varieties of tropical and subtropical herbage plants in Kenya. E. Afr. agric. J. $30: 330-338$.

Bogdan, A. V., 1965b. Vegetative propagation of fodder and pasture grasses. Kenya Fmr 105 : 33-34.

Bogdan, A. V., 1966. Plant introduction, selection, breeding and multiplication. In: W. Davies \& C. L. Skidmore (Eds), Tropical pastures. Faber \& Faber, London.

Boonman, J. G., 1967. A. Rep. Nat. agric. Res. Stn Kitale.

Boonman, J. G., 1970. Seed production of tropical grasses. Kenya Fmr 164: 15.

Borget, M., 1969. Résultats et tendances présentes des recherches fourragères à l'IRAT. Agron. trop. 24: $103-123$.

Burton, G. W., 1943. Factors influencing seed setting in several southern grasses. J. Am. Soc. Agron. 35: $465-474$.

Burton, G. W., 1966. Breeding better Bermudagrasses. Proc. 9th int. Grassld Congr. 1965: 93-96.

Carr, D. J. \& Eng Kok Ng., 1956. Experimental induction of flower formation in Kikuyugrass (Pennisetum clandestinum Hochst. ex Chiov.). Aust. J. agric. Res. 7: 1-6.

Evans, Gwilym, 1959. Seed rates of grasses for seed production I. Pasture varieties of ryegrass, cocksfoot and timothy. Emp. J. exp. Agric. 27: 291-299.

Evans, L. T., 1964. Reproduction. In: C. Barnard (Ed.), Grasses and grasslands. Macmillan, London.

Evers, A. \& J. E. Wolfert, 1959. De zaadteelt van veldbeemd. Publ. Proefsin Akker-Weideb. 7.

FAO, 1969. Report of the ad hoc technical conference on grassland management and fodder production in Africa south of the Sahara, Nairobi 1969. Meeting Rep. PL: 1969/M/6: 1-32.

Gildenhuys, P. J., 1950. Fertility studies in Setaria sphacelata (Schum) Stapf and Hubbard. Sci. Bull. 314. Government Printer, Pretoria.

Gordin-Sharir, A. \& H. Gelmond, 1966. Seed setting, production and viability of Rhodesgrass in Israel. E. Afr. agric. J. 31:365-367.

Griffiths, D. J., J. Lewis \& E. W. Bean, 1966. The problem of breeding for improved seed yields in grasses. Proc. 10th int. Grassld Congr. 1966: 749-754.

Hacker, J. B., 1966. Cytological investigations in the Setaria sphacelaia complex. Aust. J. agric. Res. 17: 297-301.

Harlan, J. R., 1970. Cynodon species and their value for grazing and hay. Review article. Herb. Absir. 40: 233-238.

Hrishi, N. J., 1952. Studies on the cytogenetics of six species of Pennisetum and their comparative morphology and anatomy. Genetica 26: 280-356.

Moore, C. E. M., 1962. A. Rep. Kenya Dep. Agric. 1962: 92.

Oomen, W. W. A., 1969. Experimental seed cleaning equipment. Proc. int. Seed Test. Ass. 34: 15-72.

Sheth, A. A., L. Yu \& J. Edwardson, 1956. Sterility in Pangolagrass (Digitaria decumbens Stent). Agron. J. $48: 505-507$.

Strange, R., 1957. Ley farming. Kenya Fmr (Jan. 1957).

Youngner, V. B., 1961. Low temperature induced male sterility in male fertile Pennisetum clandestinum. Science 133: 577.

Warmke, H. E., 1954. Apomixis in Panicum maximum. Am. J. Bot. 41: 5-11.

Wheeler, W. A., 1950. Forage and pasture crops. D. Van Rostand, Princeton, N.J.

Wilson, G. P. M., 1970. Methods and practicability of Kikuyu grass seed production. Proc. 11th int. Grassld Congr. 1970: 312-315.

Woodhead, T., 1968. Studies of potential evaporation in Kenya. Government of Kenya. 